\title{
TIME TRAVEL AND CHINGHIZ AITMATOV: EXPLORING THE RIGOURS OF MULTICULTURAL READING
}

\section{David William PARRY}

iD : https://orcid.org/0000-0003-1894-458X

Metropolitan Community Church, United Kingdom

(C) The Author(s) 2020

\begin{abstract}
At a time when the entire world seemed to be opening up for me in the 1980s, I was invited to endless "drinks dos" across London. On two occasions, I had the chance to meet a famous Kyrgyz author named Chinghiz Aitmatov, and although the opportunity to engage with him at length never fully arose, I went on to read his novels and learnt to vigorously applaud his strangely poignant imagination on a wide variety of textual levels. Indeed, it is something of a dystopian nightmare that our "youth of today" proactively shies away from Text in order to embrace the merely optical. Hence, with hindsight, by way of scrutinising his literary habits and feeling compelled to sit in the seat of my imaginary time machine, I would seek to quiz him about the reasons "Why anybody should read anything?" All in all, I suspect, a Central Asian bard of Aitmatov's stature would have suggested that apart from liberating our intelligence century-by-century from outmoded prejudices, and stretching personal brain capacity into a new-born range of empathies, the art of reading unfolds those eminently rare, but essential, hours of multicultural genius, thereby, so to speak, opening another exotic eye upon the world.
\end{abstract}

(C) 2020.All rights reserved.

\section{ARTICLE INFO}

ARTICLE HISTORY

Received:

29 July, 2020

Accepted:

18 October, 2020

Published:

30 October, 2020

Available online:

30 October, 2020

\section{KEYWORDS}

Multiculturalism, intelligence, Kyrgyz author, personal brain, multicultural 


\section{Introduction}

In ancient Eurasia, the Angel of Destiny was said to hide unexpected gifts in our future. Indeed, this was one of the reasons I called my first serious conceptualist dramatisation "Fate's Good Fortune". An edgy script still needing to see the light of an actual, physical, staging, due to the fact I present Azerbaijani President Heydar Aliyev posthumously encountering a black woman, the Sybil, on the other side of his grave. A setting, obviously, some find uncomfortable from the very outset. Contextualised so, this scenario was not inspired by either my numerous visits to Baku, or for that matter, my love of Kyrgyzstan. Rather, it sprang into being years beforehand when I moved to London from Fareham in Hampshire. A time when the entire world seemed to be opening up for me and I was invited to endless "drinks dos" across the city as an ambitious young British poet. Recalled further, one such event was to be held by some Russian friends in an exceedingly fashionable neighbourhood. A datum my treasured associates interwove with their invitation, along with the certainty I would have the chance to meet a famous Kyrgyz author named Chinghiz Aitmatov (1928-2008).

Cryptically adding, if I recall correctly, he "was a man I should want to meet". Now, as the cherubim will have it, I could not attend this particular event and asked them if the author was going to be present at any other "function"; a term commonly used in that long lost epoch of fundamental cultural transition currently known as the 1980s. Overall, their response proved puzzling, even though I was told he would be at another gathering relatively soon. A "bash" I was equally welcome to attend, although meeting him face-to-face would prove a little more difficult, because it would be a much more formal occasion. Anyway, I turned up at this second jamboree with a wild expectancy; an excitation which was only partially fulfilled. After all, there was a man stood in the far corner of a room whom people said was Aitmatov. What is more, he looked like Aitmatov from a distance and matched every single description of the author I had ever been given. Yet, I could not get any closer. All meaning, I have never really been sure whether I encountered the great writer, or not! However, be it that way or this, I went on to read his novels and learnt to vigorously applaud Aitmatov's strangely poignant imagination on a wide variety of textual levels.

With hindsight, the main question I was going to quiz him about was "Why should anybody read anything?" Certainly, when everything has been spent and spoken, it is something of a dystopian nightmare that our "youth of today" proactively shies away from Text in order to embrace the merely optical. Clearly then, it is Manga instead of Christopher Marlowe (1564-1593) that governs their 
fantasies. A depressing verity both here in Britain, as well as across Central Asia. A phenomenon, moreover, boding somewhat badly for general literacy, as well as multicultural thinking. Well, all of the above confessed, it remains vital to remember that printed books have never simply been limited to instructional manuals, textbooks, resources for homework, or explanations of economic theory. Indisputably, they have unendingly been aligned to mystical pleasures, transcendent beauty, ancient folklore and culturally significant history. Exemplified, as this is, by fabled leather-bound volumes of spells consulted by wizards in cartoon comics: all the way to genuinely alchemical texts in a philosophical novelist's well-crafted satire, through to the conjuration of an entire world in Shakespearean theatre scripts.

Each in itself, evidencing that the published page has perennially exerted a revolutionary influence over entire societies. Also demonstrating, if any further illustration be necessary, that physical texts are infinitely more than convenient linguistic storage systems, a cheap form of entertainment, or a two-for-one birthday gift near the check-out in a local supermarket. Plainly, a book (when it proves worthy of this title), evokes the nascent luxury of discovering uncannily obscured personal dreams, along with previously hidden vectors inside our expansive Selves. And all within a sumptuous object discernible as an investment, on the one hand, as well as a collectable artefact, on the other. Possibly being some of the reasons why Gustave Flaubert scribbled, "Do not read, as children do, to amuse yourself, or like the ambitious, for the purpose of instruction. No, read in order to live"; ${ }^{1}$ a sentiment with which Aitmatov would have completely concurred. Sympathised thusly, reading is akin to other aesthetic elations. It is the opening of another exotic eye, so to speak, besides being the empowerment offered by an extra brain. Hence, connoisseurs have long argued that reading permits us to participate in the Sacred. Partly deciphering, perhaps, why bejewelled editions of the Holy Koran, or our Blessed Bible, have themselves become invested with powers and portents of their own!

\section{The significance of research}

Some shallow critics, this demonstrated, seem to question the act of reading altogether. Instead, somewhat abnormally, of realising every book is a delectable papier-privilege, they publically pride themselves (as unmistakable textual virgins) on their ignorant naivety. Simultaneously trumpeting their lack of sophistication and erudition as though such failings were a type of streetwise virtue. For people like these, the whole idea of reading a book as collaboration with life-transforming

\footnotetext{
${ }^{1}$ J. C. Tarver, Gustave Flaubert as Seen in His Works and Correspondence (Westminster, 1895), pp. 233-234.
} 
concepts, or as an ally to other adventurers in parallel textual worlds, is simply incomprehensible. Alternatively, they prefer to abandon the heady gestalt of authors such as Chaucer, Voltaire, Lawrence Sterne, Darwin, Sir Richard Francis Burton, Thomas Manning, Rabindranath Tagore, Jonathan Swift and Charles Dickens, in order to wallow inside their own reductive sphere. Analogous, many would say, to someone who enjoys the narrow confines of a prison cell, while refusing to look through their iron-barred windows at the Elysian Fields beyond! These truly inadequate interlocutors, therefore, refuse to regard literature respectfully. Furthermore, precisely because they find the prospect of reading so personally off-putting, these self-styled advocates of immediate gratification remain unable to raise their spirits through ecstatic eloquence, blissful rhyme, or even the clever intricacies of meagre wordplay. Eventually discovering, the above recorded, that they are far beneath the rudimentary skill-sets demanded by prevalent social intercourse.

Contrarily, at the other end of this dialectical spectrum, stand Russianspeaking Central Asians like Aitmatov. A man who grew up encompassed by works of global literature, along with the ageless poetry of his nation. So remembered, on the plane of elementary history, my wonderful colleague was born to a Kyrgyz father and Tatar mother; each of whom worked as civil servants in Sheker. A profession, oddly, forcing his father to officially deny accusations of "bourgeois nationalism" when push finally came to political shove. Charges, this recollected, seemingly motivated by governmental paranoia, as well as Aitmatov senior's fascination with received cultural praxis. Regrettably then, following this gross injustice, Aitmatov's father was arrested, and later executed in secret; somewhen around 1938. Anyhow, his son, thankfully, appeared irrepressible and eventually became an integral member of the legendary post-war generation of Russianlanguage writers. An improbable attainment if one is mindful that Chinghiz Aitmatov's own output before his novel Jamila was not particularly impressive. Undeniably, it only consisted of a few stories and a short novella called Face to Face. Nevertheless, Jamila unarguably evinced the author's literary worth, because its rich narrative tells an outstanding tale of universally recognisable romance. A recitation (seen through the eyes of an adolescent boy), of how Jamila, a village girl separated from her soldier husband by the Second World War, falls in love with a tragically disabled soldier staying in her village. Every and each misadventure played out against the age-old diegesis of gathering and transporting life-sustaining grain crops to adjacent markets. Other novels of visceral account include, Farewell, Gulsary!; The Day Lasts More Than a Hundred Years; The White Ship; and The Scaffold: albeit always measured against the enduring success of this epic. So, despite severe initial turbulence, Chinghiz Aitmatov was awarded the Lenin Prize in 1963 for his Tales of 
the Mountains and Steppes, whilst Aitmatov's artistry gained international recognition among layman and specialists alike during the years ahead.

\section{Chinghiz Aitmatov's works as a gift of fate}

Interestingly, Aitmatov's oeuvre appears to embody some elements unique to his personal creative processes. Critics frequently observing that his work draws heavily on regional folklore, but not in the traditional sense. Rather, somewhat cunningly, they unravel Aitmatov's remoulding and reinvention of inherited oral diatribe (within the boundaries of modern life) as a stylistic feature running throughout his corpus. By the same token, these pundits postulate that in nearly every parable, Aitmatov interweaves universal myth, or a well-known fairy tale, with mundane phenomenologies as a telling touchstone for his accounts. For instance, one may descry in The Day Lasts More Than a Hundred Years Aitmatov's masterful grasp of a Kyrgyz fabulism chronicling a young captive turned into a "mankurt" (an unthinking slave); all serving as a calamitous allegory about our drear human condition. Each literary metamorphosis escorted by a second aspect of Aitmatov's writing easily discovered through his intimacy with the animal kingdom. ${ }^{2}$ An ecological stance far ahead of his day, whilst inseparably connecting Aitmatov's chirography to the development of new "transpersonal paradigms" in prose. Wherefore, as he explained in one of his innumerable interviews, these concerns entailed descriptive circumstances in English, as much as Russian and his native Kyrgyz, regarding an issue largely ignored across our globe. ${ }^{3}$ A confession assisting scholars to apprehend why his early jottings were mostly composed in Kyrgyz; some later being translated into Russian by his own hand, whereas others were translated into the English language by a small army of unknown translators.

To scrutinise his literary habits further, Aitmatov lived during a period when Kyrgyzstan was transforming from one of the most remote lands in the Russian Empire into a republic of the USSR. Explicating why, no doubt, this future author and diplomat had previously studied at a Soviet school in Sheker, as well as the biographical evidences detailing the juvenile Aitmatov working from an unusually early age. By fourteen, he was an assistant to the Secretary of his Village Soviet.

\footnotetext{
${ }^{2}$ G. T. Çetin, 'An Animal-Standpoint Reading of Farewell Gul'sary by Chingiz Aitmatov', Furat Üniversitesi Sosyal Bilimler Dergisi 30 (2020), pp. 29-39.

3 I. Melnikova, 'Ирина Мельникова: Работу над сборником Айтматова считаю подарком судьбы' ('Irina Melnikova: I view the opportunity to work on Aitmatov's Collected Works as a gift of fate'), Вечерний Бишкек (Evening Bishkek), 27 May 2015, https://www.vb.kg/doc/314306_irina_melnikova:_raboty_nad_sbornikom_aytmatova_schitau_p odarkom_sydby.html (Accessed 12 October 2020)
} 
Following this appointment, he held down jobs as a loader, tax collector, and engineer's assistant, while experimenting with many other types of employment as he matured. Relatedly, by 1946, Aitmatov began studying at the Animal Husbandry Division of the Kirghiz Agricultural Institute in Frunze, but shortly afterwards switched to literary studies at the Maxim Gorky Literature Institute in Moscow. A city he called home between 1956 and 1958. Thereafter, (for eight years approximately) he worked for the newspaper Pravda before examining his professional options. Curiously, Aitmatov's own Russian-language projects first appeared in print as early as 1952. Echoing, presumably, a comprehensive process of lexical blossoming immediately spotted by his admirers in volumes like "The Newspaper Boy Dziuio" and "Ашым". Still, his initial publication in Kyrgyz entitled White Rain, along with his well-known saga Jamila adorned popular bookshelves by 1958. Predictably then, by 1961 he was propelled into becoming a juror at the second Moscow International Film Festival, whereas 1971 saw Aitmatov climbing the ladder of literary recognition as a juror for the seventh Moscow International Film Festival. Ascending again, 1994 found Aitmatov on the jury of the 44th Berlin International Film Festival. A far from insignificant achievement bearing in mind previous Cold War anxieties. Finally, by 2002, he was recognised as the judicial President at the 24th Moscow International Film Festival. Obviously, a suggestive post due to reminiscences that film had once been seen as largely "decadent" and requiring a nod of assent from the literati in order to attain its just, as well as rightful, place at this supernal table.

Observed so, we all have our Existence in fatefully calculated time, whether we stride the planetary stage as literary giants, or unambiguously persist as innocent tradesfolk. Hereafter, following years of minor ailments, Aitmatov suffered kidney failure; being admitted on 16th May 2008 to a hospital in Nuremberg, Germany, where he died of pneumonia on 10th June at the age of 79. After his passing, Aitmatov's body was flown to Kyrgyzstan, wherein a number of national civic formalities marked his demise, before a full ceremonial burial in the Ata Beyit cemetery. A location, in all likelihood, where his father was also laid to rest. Demonstrably, the above pondered, Chinghiz Aitmatov's obituary was published in The New York Times as a testament to tensions that post-Cold War manias could only permit a grudging eulogy, which declared him, "a Communist writer whose novels and plays before the collapse of the Soviet Union gave a voice to the people of the remote Soviet republic of Kyrgyz", adding that Aitmatov "later became a friend, diplomat and adviser to the Soviet leader Mikhail Gorbachev".4

4 B. Weber, 'Chingiz Aitmatov, Who Wrote of Life in U.S.S.R., Is Dead at 79', The New York Times, 15 June 2008, https://www.nytimes.com/2008/06/15/books/15aitmatov.html?ref=obituaries (accessed 09 October 2020). 
Henceforth, sitting in the seat of my imaginary time machine, I will now ask him the questions I had intended to say on that fateful evening way back in the 1980s in a manner remindful of Louis Aragon. A delightful conceit, beginning with what he thought reading actually was in reality. ${ }^{5}$ Already then, in my mind's third eyeball, I can glimpse dawn and dusk reversing like the flapping wings of a great bird. Until, this settled, I can clearly hear him replying that reading is a complex "cognitive process" of decoding symbols in order to derive, or construct, "meaning" (ordinarily defined as "comprehension" in educationalist circles) and "value". Staggeringly, an answer like this would imply reading is intersubjective, albeit transparent, self-directed, communication. Contrastingly, it can equally lead to informational exchange, language acquisition, and the sharing of ideas: let alone a foreshadowing of aesthetic and proportional notions in apportioned terms. Understood thuswise, linguistic semiosis is typically, as well as "ironically", visual (printed, or written), besides being tactile when transcribed into Braille. Thence, regardless of language specificity, reading is best envisaged as a sophisticated interaction betwixt Text, Culture, Society, and individual Readers. A continuum, dare one propose, moulded by a particular reader's experiences, prior knowledge, and psychological attitude towards the Absolute. In other words, it is both collectively objective, as well as subjectively focussed. All contentions implying the process of reading involves continuous practice and refinement. Atop of which, reading entails critical analysis and an honest creativity in its practitioners. Each consumer of literature venturing into a potential galaxy of metaphysical assignations with words, characters, phrases, plots and alien geographies, derived from those untrodden territories. Whenceforth, reading is such a complex process that it cannot be controlled, or restricted, to one or two putative interpretations. Consequently, at this juncture, I may have asked Aitmatov if (since there are no concrete laws of reading) these procedures allow a reader to escape the incarcerating sensorium around him, or her; and, thereafter, produce their own linguistic landscapes introspectively. An unsettling thought propounding that every reader will have her, or his, own Jamila in the depths of personal consciousness. One way or another, this theorised, every reader will inevitably employ an artillery of strategies in order to assist with the necessary decoding of these signs, marks and images. In this sense, contextual clues build patterns of rapport amid a reader and a text. Identifying, thereby, the importance of unknown values, or unlived empiricisms. Beyond doubt, this is a sentient textual "interplay" linking subjective apprehensions to an already existing framework of knowledge, or agreed multicultural schema.

${ }^{5}$ Nowadays, these questions would be adjoined to my personal thanks for inspiring me with the idea of "Theatrical Poetry". Indeed, without Aitmatov, my two collections of dramatised prosepoetry, Caliban's Redemption and The Grammar of Witchcraft would not have been written. 
Stunned quite possibly at his reactions, my third question would have centred on the history of reading. An enterprise dating back to the invention of writing itself and, all things considered, a genuine miracle of human creativity taking place during the fourth millennium BC. Assuredly, Aitmatov knew reading printed text is now a commonplace for the majority. An accepted truism whereby everyone knows information is effortlessly accessed by a variety of means throughout our society. But, this is a recent step in Western cultural affairs. Ergo, it is indispensable to recall (with minor exceptions) that only an extremely small percentage of people in most European countries could be considered literate before the Industrial Revolution. A necessary clarification when considering so-called "pre-modern" cultures, which could boast of high literacy rates: precedents being unearthed in the case of Classical Athens, as well as the Islamic Caliphate. Palpably then, unlike creative writers, academicians assume these habituations were partially enhanced by "reading aloud" - a widespread activity back in antiquity, whilst reading silently to oneself was said to be infrequent. As an instance in focus, scholars tend to refer to Confessions by Saint Augustine, wherein he states Saint Ambrose's personal custom was to read vociferously to himself. ${ }^{6}$ Implying, of course, it was not until the Age of Enlightenment that "elite" citizens began to promote quiet, or passive, reading practices, rather than verbally articulated Text. Yet, even if this is admitted for the sake of argument, reading still has no guidelines. Contrariwise, it is a way to gain one's own grip on intended information interiorly; a habit wherein deep explorations of Text become possible. Penned so, construction, or the creation of writing systems, along with the subsequent manufacture of linguistic "items", was believed to be an indication of someone's healthy participation in their surrounding society. An opinion sustaining bookshops to this haunted day. Nevertheless, in those bygone decades, readers were considered model citizens simply because they did not create an actual "product". All proving, they were not dangerous political subversives, or literary crazies, looking for novelty and endless hedonism. Henceforth, reading was viewed as an obviously inferior art to writing, but one of singular importance to the essential structure of our cultural bonds. Weirdly, I can see Aitmatov listening intensely to these cogitations, although unsure of the implications concealed behind this indistinct allegation. Yet then again, maybe I am watching him engrossed in pure speculation.

So detected, I would have reminded him that in eighteenth-century Europe, the (then new) delectation of reading alone in bed was thought to be immoral; if not actually hazardous. Reading, when all said and done, aroused one's fancies and fleshly tastes. Accordingly, the moment reading became less of a diurnal occurrence

\footnotetext{
${ }^{6}$ Augustine, Confessions, (trans.) C. J.-B. Hammond (Cambridge, MA, 2014), p. 243.
} 
and something more personally exclusive (a routine taking place inside individual bedrooms as opposed to dormitories, or familial sleeping areas), a sensibility of dread comparable to other menaces and indecencies begins. Back then, "experts" even went as far as stating this convention was akin to an unmanageable fire caused by bedside candles, or the problems posed by an unchaperoned spinster. Recollected thuswise, it can be intuited that reflexive multicultural critiques were patently focussed on a fear that readers - especially women - could escape their national and tribal obligations. Transgressing, thereby, "ethical boundaries" and losing themselves in an addictive fantasy world. Each scholarly analysis, peculiarly, indicating there are several modes, along with types, of reading. Moreover, once studied, anyone reflecting on this topic rapidly discovers that differing rates of processing information can be attained with regard to different kinds of materials; whether this leads to a private state of reverie, or otherwise. For example:

- Speed reading - is a collection of methods for increasing reading speed without an unacceptable reduction in comprehension, or individual retention.

- Subvocalized reading - combines sight-reading with the internal sounding of words; as if spoken aloud. Advocates of speed reading, however, claim it can be a bad habit in that it slows reading and comprehension down, whilst others indicate the reverse, particularly with abstruse types of text.

- Incremental reading - is a reading discipline designed for long-term memorisation. It means, after all, "reading in portions".

- Rereading - is reading a text more than once and, as Vladimir Nabokov said, "It allows for a more profound emotional connection and selfreflection, versus the first reading which is more focused on the events and plot".

- Proofreading - is a kind of reading for the purpose of detecting typographical errors. One can learn to do it relatively quickly, although professional proofers typically acquire this ability over extended periods of time.

On top of which, a number of readers take notes when they read. Thenceforth, some readers:

-Survey-question-read-recite-review - a methodology, often taught in colleges, whereby one is able to externalise material without having to refer to notes during a lecture. 
-Structure-proposition-evaluation - a technique allowing readers to gauge the merits of an argument, or conclusion.

- Rapid-serial-visual-presentation - a system involving the presentation of words in a sentence (albeit one at a time), wherein a reader's eye movement is trained for an increased reading velocity.

- Multiple (intelligences) focus - a craft drawing upon a reader's diverse ways of thinking in order to enrich his, or her, appreciation of a text.

Everything above considered, reading processes are contexts of communication on either a superficial or depth scale, depending on one's intentionality. Inevitably, performing this act successfully in comfortable restaurants, private rooms, study areas, libraries, cafés, trains, or at bus stops, let alone in parks, or woodlands, ultimately depends on the available light source; along with the time of day. Something enhanced, or troublingly hindered, by the clarity of the printed word itself: whether written in ink, or inscribed in toner; as well as the quality of paper that words are printed upon. Besides, "transmissions" of information depend on the modus of "transference" - like a magazine, book, leaflet, notepad, newspaper, or electronic display. Nowadays, this appreciated, such devices as a television, mobile phone, and iPad, et al, further extend our opportunities for Text to be digested. Still, even though outlets for inscription are duly enlarged, handwritten text continues to be generated using a pen, or graphite pencil, at the same time as short texts can be engraved, painted, or written, on an object; along with the traditional medium of paper. Analogously, a text may be creatively associated with Art, while the calligraphy of an address on an envelope, or the semiotics of a street sign to traffic, or commercial packaging around a product, unveil subsidiary evolutions in our alphabets. Unquestionably, even political slogans painted on a wall can also convey multileveled meanings in similar ways to carefully arranged coloured stones on a beach.

Naturally, once pictured from this much wider perspective, the relevance of the Global Text Project becomes increasingly apparent for overtly deprived groups. Assessed so, this "not-for-profit" institute is magnanimously dedicated to the translation, printing, and distribution of free open-content textbooks throughout the Internet, as well as an overall understanding of Text-In-Itself. Strikingly, it is an open educational resources (OER) project concentrating on university students in "developing countries", where textbooks are normally expensive and literature is perceived as a total luxury. All making me wonder what Aitmatov's reaction would have been at this stage of our conversation; notwithstanding any mention being made of Abai Qunanbaiuly (1845-1904) as a potential counterpoint, or the resistance to reading witnessed outside our schools? So mused, textbooks remain a crucial 
commodity for higher education, despite being increasingly hard to attain: even in "First World" economies like the United States. Undeniably, between 1998 and 2014 textbook prices rocketed by 161 per cent. ${ }^{7}$ In addition, since 1977, handbook prices have risen by 1,041 per cent: more than triple the standard rate of American inflation. ${ }^{8}$ Unacceptably then, the two major reasons lurking behind these outrageous costs are inapt publication practices, shepherded by the extra material bundled (unnecessarily) into "cutting-edge" monographs. ${ }^{9}$ Each a factor explaining why this project relies heavily on volunteers. Quite apart from which, this organisation experienced a number of (direct) challenges regarding its engagement with unremunerated translators in languages other than Spanish. Resulting, the above noted, in volunteers being enrolled from among the ranks of graduate and college students who are already bilingual. Simultaneously, other volunteer-based enterprises, including established academic "communities" such as Translations without Borders and Translators for Progress have come to their aid, whilst the selection of a volume for translation is regularly a subject of heated debate. Yet, once a manual has been chosen for translation (a choice evaluated on global needs and the availability of translators), the work under scrutiny is allocated to a "virtual team" of exegetes. Oh my, I can only guess at Aitmatov's utterances about a radical project of this sort! At any rate, by 2007 this humanitarian undertaking started to receive funds from the Jacobs Foundation of Switzerland. A financial advancement permitting it to relocate, as well as hold a pilot test run, for its monumentally ambitious plans. It goes without saying, of course, that the idea behind Global Text's original intention was to share open-content textbooks in English, Chinese, Arabic, Russian and Spanish: each title freely available through their website. That being joyfully declared, their website presently sports over one hundred primers in English, even though the quantity of print editions in Chinese and Spanish still need to radically increase.

\section{Conclusion}

Thereupon, my imaginal time machine must return to our present period, because, unforeseeably, we can clock the rub. Either, reading is destined to unfetter

\footnotetext{
7 C. Straumsheim, 'Triaging Textbook Costs', Inside Higher Ed, 16 August 2015, https://www.insidehighered.com/news/2015/08/04/era-400-college-textbook-affordabilityinitiatives-take-utilitarian-approach (accessed 12 September 2020).

8 B. Popken, 'College Textbook Prices Have Risen 1,041 Percent Since 1977', NBC News, 6 August 2015, https://www.nbcnews.com/feature/freshman-year/college-textbook-prices-have-risen812-percent-1978-n399926 (accessed 12 September 2020).

9 N. H. Nicholls, 'The Investigation into the Rising Cost of Textbooks', Scholarly Publishing Office University of Michigan Library (17 August 2015), https://apps.lib.umich.edu/files/SPOTextbookBackground.pdf (accessed 12 September 2020).
} 
the human mind, or our collective psyche will continue to be pasty, weak, pallid, and grossly under-stimulated. Embodied, as these dismal conditions are, by the withered white flowers inside my pocket. So attested, reading is a pursuit marking this process as the true sorcery and enchantment of Text in a nutshell. A power enhanced, when all tallied and quantified, by the obvious veracity of those claimants contending that reading continues to be our best method of recognising the heart of a frequently heartless world. So, in addition to being the most straightforward means through which readers can enquire into the subtle activities of Soul, in a seemingly soulless world, reading proves essential to the extension of empirical self-awareness. Atop this, reading is the principal technique enabling literary art to enlarge spontaneous perception in anyone - at any time. Wherefore, reading is best seen as an authentically anagogical force of charged sentences, magnetised grammar, and galvanised paragraphs. Every one of them quickly translating into public enlightenment, multicultural justice, and humanitarian concern. In which case, I, buttressed by the great man of letters himself, commend this ageless custom to one-and-all. Answering, therein, my dolefully adrift question "why should anybody read anything?" with a robust retort. Provided, that admitted, I heard him correctly down the timeline. But, I digress. Visibly, a bard of Chinghiz Aitmatov's stature would have finally concluded our conversation by turning towards me and saying that apart from liberating our intelligence centuryby-century from outmoded prejudices, and stretching personal brain capacity into a new-born range of empathies, the art of reading unfolds those eminently rare, but essential, hours of intersubjective genius.

A factor never completely exhausted by our energised ancestors, or reduced to mere triviality between ourselves.

\section{Disclosure statement}

No potential conflict of interest was reported by the author.

INTERNATIONAL

JOURNAL OF

MULTICULTURALISM 